\title{
RESUMO
}

V.7 • N.3 • Julho -2019

ISSN Digital: 2316-381X

ISSN Impresso: 2316-3321

DOI: 10.17564/2316-381X.2019v7n3p93-104

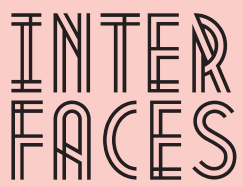

CIENTÍFICAS

\section{FEMINISMO JURÍDICO COMO INSTRUMENTO DE RUPTURA COM O DIREITO PATRIARCAL}

FEMINISMO JURÍDICO COMO INSTRIMENTO DE RUPTURA CONEL DERECHO PATRIARCAL

LEGAL FEMINISM AS AN INSTRUMENT OF BREACH WITHPATRIARCHAL LAW

Cídia Dayara Vieira Silva da Conceição ${ }^{1}$ Bruna Laís Silva Pinto ${ }^{2}$

Salete Maria da Silva ${ }^{3}$

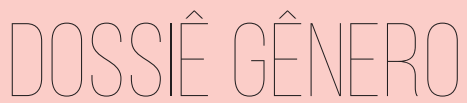

0 Direito é uma forma eficiente de poder e, como tal, não é a solução para todos os problemas, uma vez que produz consequências paradoxais e pode, mesmo com as melhores intenções, contribuir para a promoção de estereótipos e a solidificação de iniquidades. Nesse sentido, a práxis jurídica demonstra que o direito patriarcal, marcadamente gendrado, caminha a largos passos, à medida que temos um ensino jurídico que ainda forma profissionais engessados e aptos a aplicar apenas a letra fria da lei, sem realizar a exegese necessária em termos direitos das mulheres, para os quais ainda são uma incógnitas, dado o déficit de sua formação do profissional. É bem verdade que a opressão das mulheres vai muito além da divisão sexual do trabalho, da ênfase na biologia e da aplicação equivocada das normas, isto é, dos ranços do patriarcado, pois todos estes fatores trabalham imbricados de forma a impedir a ascensão das mulheres. No campo do Direito, essa espécie de dominação parte do operador do direito e constitui verdadeiros entraves para a aplicação dos diplomas legislativos em favor das mulheres, ou seja, o Direito funciona como mais um perpetuador de distorções de gênero, quando deixa de ser utilizado para promover a igualdade material e a equiparação social.

\section{PALAVRAS-CHAVE}

Androcentrismo. Patriarcado. Violência. Gênero. Direito. 


\section{ABSTRACT}

Law is an efficient form of power and as such is not the solution to all problems, since it produces paradoxical consequences and can, even with the best of intentions, contribute to the promotion of stereotypes and the solidification of inequities. In this sense, legal praxis demonstrates that patriarchal law, which is markedly gender, is striding forward, as we have a legal education that still forms professionals who are plastered and able to apply only the cold letter of the law, without performing the necessary exegesis in terms women's rights, for which they are still unknown, given the shortage of their professional training. It is true that the oppression of women goes far beyond the sexual division of labor, the emphasis on biology, and the misapplication of norms, that is, the ranks of patriarchy, for all these factors work so closely as to prevent the rise of women. In the field of law, this type of domination is part of the rule of law and constitutes a real obstacle to the application of legislative instruments in favor of women, that is, law acts as another perpetuator of gender distortions when it is no longer used for promote material equality and social equality.

\section{KEYWORDS}

Androcentrism. Patriarchate. Violence. Gender. Right.

\section{RESUMEN}

El derecho es una forma eficiente de poder y, como tal, no es la solución a todos los problemas, ya que produce consecuencias paradójicas y puede, incluso con las mejores intenciones, contribuir a la promoción de estereotipos y la solidificación de iniquidades. En este sentido, la praxis jurídica demuestra que el derecho patriarcal, marcadamente ingeniado, camina a largos pasos, a medida que tenemos una enseñanza jurídica que aún forma profesionales enyesados y aptos para aplicar solo la letra fría de la ley, sin realizar la exégesis necesaria en términos derechos de las mujeres, para los que aún son unas incógnitas, dado el déficit de su formación del profesional. Es verdad que la opresión de las mujeres va mucho más allá de la división sexual del trabajo, del énfasis en la biología y de la aplicación equivocada de las normas, es decir, de los rancios del patriarcado, pues todos estos factores trabajan imbricados para impedir el ascenso de las mujeres. En el campo del Derecho, esa especie de dominación parte del operador del derecho y constituye verdaderos obstáculos para la aplicación de los textos legislativos en favor de las mujeres, es decir, el Derecho funciona como otro perpetuador de distorsiones de género, cuando deja de ser utilizado para promover la igualdad material y la equiparación social. 


\section{PALABRAS CLAVES}

Androcentrismo; patriarcado; violencia; género; derecho.

\section{INTRODUCÇÃO}

A realidade fática tem demonstrado que se faz urgente e necessária uma mudança de paradigmas no mundo do Direito, tendo em vista que, apesar do Brasil ter uma das Constituições mais democráticas do mundo e ser signatário dos mais importantes tratados internacionais em matéria de direitos humanos das mulheres, a práxis jurídica cotidiana ainda está muito afastada destas questões e pretensões de igualdade, notadamente em termos de relações de gênero.

A história das instituições jurídicas no Brasil consolidou a ideologia positivista, sobre a qual a lei formal é o fundamento principal da validade das condutas dos indivíduos na sociedade. De tal sorte, o texto da norma jurídica é sempre o ponto de partida para a interpretação da realidade, notadamente quando se trata de realização da justiça no caso concreto. Todavia, há um consenso social de que o Direito só terá razão de ser na medida em que encaminhe de forma justa as questões que surgem no dia a dia das pessoas.

Em verdade, existe um abismo entre o direito positivado e o direito aplicado, pois, embora exista uma gama de Tratados Internacionais, a própria Constituição Federal e a legislação infraconstitucional, todos se reportando à necessidade de tratamento isonômico entre os gêneros, ainda persiste um padrão de direito gendrado, de forte caráter patriarcal.

Diante disso, nem o feminismo, com seus sustentáculos influenciando nas mais diversas produções dos campos sociais e políticos, conseguiu adentrar de forma perspicaz e definitiva, na seara jurídica, dado o caráter ainda hermético, elitista e pretensamente neutro do campo jurídico (SILVA, 2018). Neste contexto, vale pontuar que o Estado possui uma arquitetura de opressão historicamente delineada, o que dificulta a compreensão das especificidades do feminismo jurídico sem observar os fundamentos epistêmicos e androcêntricos que, por vezes, não reconhecem a cidadania das mulheres (VALENTE, 2000).

De outro lado, as opiniões feministas com relação a função e a utilidade do Direito foram se diversificando e se tornando complexas, uma vez que, ao largo da jornada, ora o direito é visto como mecanismo de dominação masculina, ora é percebido como instrumento de aprimoramento da dessa cidadania feminina (SILVA, 2018).

Em linhas gerais, o direito é fruto das sociedades patriarcais e sexistas, por esta razão, acaba reforçando os interesses masculinos. E, quando contempla os interesses ou demandas das mulheres, continua sendo aplicado por instituições e profissionais moldados por uma ideologia patriarcal (MELLO, 2012).

Pelas práticas de teóricas, ativistas e militantes de diversas feministas, percebeu-se a necessidade de o feminismo adentrar cada vez mais à seara jurídica e estabelecer com esta uma relação de crítica 
mútua, mas também de importantes parcerias. Afinal, o Direito só terá razão de ser na medida em que encaminhe de forma justa as questões que surgem no cotidiano das pessoas (SILVA; WRIGHT, 2016).

Como qualquer outra vertente do feminismo, o jurídico, conforme Silva (2018), está caracterizado pela pluralidade, heterogeneidade e ausência de consensos, dando espaço para o desenvolvimento de inúmeras abordagens, perspectivas e propostas de intervenção, já que é justamente nessas tensões que tanto o conhecimento como o direito são delineados. É bem verdade que há um crescimento acentuado de grupos conservadores e reacionários na política institucional brasileira, assim como certa decadência das estruturas democráticas, mesmo assim é importante que o feminismo e o direito atuem de forma a garantir direitos e não os retirar. Diante disso, há que se observar que o principal problema consiste na visão do operador do direito, que mascara a sua faceta androcêntrica por meio da suposta imparcialidade e objetividade apresentadas como requisitos de validade jurídica.

De toda sorte, o que a práxis jurídica nos mostra, é que o Direito patriarcal, eminentemente gendrado, caminha a largos passos, à medida em que ainda temos um ensino jurídico dedicado a formar profissionais engessados que, em sua maioria, aplica apenas a letra fria da lei, sem realizar uma exegese mais crítica e aprofundada, por meio da qual direitos das mulheres poderiam ser valorizados e não tratados como incógnitas. Essa problemática decorre, também, da formação do profissional do direito, que nem sempre possibilita uma aproximação com as teorias feministas. Neste contexto, é de suma importância a capacitação dos operadores do Direito, para que apliquem as chamadas lentes de gênero e utilizem o aparato jurídico de modo transformador de vidas e realidades (MELLO, 2012).

Diversas autoras, como Facio (1999), Silva (2018) e Vargas (2011) tem pontuando que o Direito androcêntrico não serve mais para as demandas da sociedade, fazendo-se necessário entender que o feminismo, enquanto movimento e pensamento transformador, não só pode como deve ser fundamento para fins de implementação dos objetivos da Carta Magna. No entanto, o que se percebe é uma distância cada vez maior entre os estudos do Direito e o pensamento feminista, sobretudo nos cursos jurídicos mais voltados para a compreensão unicamente técnica do Direito.

Por essa razão, a crise que se estabelece, com o avanço do perfil conservador-androcêntrico, impõe uma disseminação maior das teorias feministas do Direito, que nos auxiliam na compreensão da interface entre o mundo jurídico e as questões de gênero, buscando auxiliar na implantação das lentes de gênero no campo do Direito, tudo com vistas a alcançar uma sociedade mais igualitária.

E nessa linha, não se pode perder de vista que a união do Direito com o feminismo constitui medida de urgência, por meio do feminismo jurídico, a fim de que, juntos, realizem as transformações sociais essenciais que nosso tempo estar a exigir.

Compreender o feminismo jurídico, enquanto fenômeno em ascensão, que se faz imprescindível para a pauta feminista, mas não só para ela, como também toda pauta humanitária, é tarefa primordial, uma vez que o feminismo jurídico pode nos conduzir a um novo paradigma sem o qual não é possível falar em direito, afinal, Direito sem feminismo, pode ser compreendido como qualquer coisa, menos como Direito. 


\section{ALGUNS APORTES TEÓRICOS}

Algumas autoras como Silva (2018) e Campos (2014), tem pontuado que a concepção gendrada do Direito advém da ideia de que ele fora inicialmente proposto exclusivamente por homens e para homens, notadamente os brancos, potentados e heterossexuais. Nesta linha, a percepção do Direito tem como pressuposto a intenção de perpetuar os interesses masculinos, por meio da manutenção de sua visão na elaboração e aplicação das normas.

A ideia de que o Direito consiste em uma prática, mas também em um discurso, e como tal, traduz formas de promover a estratificação das estruturas de poder, também pode, por meio de uma mudança paradigmática, servir à transformação social.

O conceito de Direito como discurso é trazido por Alda Facio (2003, p. 21), para quem:

Reconocer que el Derecho es un discurso del poder, tanto del poder estatal como de los múltiples poderes locales, nos dice esta crítica, nos llevará a poner atención, más que a la norma formal, a cómo ella establece las reglas, pensamientos, actitudes y comportamientos que la norma presupone e incorpora, así como a poner atención a la forma cómo la norma institucionaliza lo que debe ser considerado como legítimo o ilegítimo, aceptable o inaceptable, natural o desnaturalizado. El estudio del Derecho como discurso puede ser clave para las mujeres porque puede demostrar cómo el Derecho es patriarcal más allá de la norma, aun la norma protectora de los derechos de las mujeres.

Denota-se, buscando visibilizar as distorções e os anacronismos do Direito, enquanto discurso, a necessidade de se introduzir lentes de gênero na atividade jurídica a fim de se perceber o quão androcêntrico e patriarcal é o mundo jurídico, utilizando-se das facetas de neutralidade e objetividade para perpetuar desigualdades, especialmente entre os sexos.

E é exatamente o discurso da objetividade e neutralidade onde se ocultam as verdades faces do Direito patriarcado, pois o seu postulado de sujeito universal, enquanto titular de todos os direitos humanos, mascara a omissão das diferenças existentes entre os sexos, assim como entre outros marcadores sociais.

Aqui, insta esclarecer que a utilização da terminologia sexo no lugar de gênero, tem por pressuposto a ideia de que gênero constitui uma construção social e histórica, que se distingue da diferença biológica do sexo as experiências sociais estabelecidas com base no gênero, como pondera Joan Scott (1989, p. 3):

No seu uso mais recente, o "gênero" parece ter aparecido primeiro entre as feministas americanas que queriam insistir no caráter fundamentalmente social das distinções baseadas no sexo. A palavra indicava uma rejeição ao determinismo biológico implícito no uso de termos como "sexo" ou "diferença sexual". O gênero sublinhava também o aspecto relacional das definições normativas das feminilidades. As que estavam mais preocupadas com o fato de que a produção dos estudos femininos centrava-se sobre as mulheres de forma muito estreita e isolada, utilizaram o termo "gênero" para introduzir uma noção relacional no nosso vocabulário analítico. 
Assim, gênero pode ser entendido como um conceito analítico que vem sendo utilizado para se compreender as diversas formas de opressão de um sexo sobre o outro, isto é, do homem em detrimento a mulher. Portanto, há que se constatar que a criação de um sujeito neutro é uma forma de perpetuar as diferenças, donde se sabe que a igualdade formal não efetiva a aplicação do Direito justo, haja vista que as diferenças e as diversidades têm que ser analisadas para a efetiva aplicação do direito.

Nesta linha, a afirmação “homens e mulheres são iguais perante a lei” só faz sentido no que concerne o alcance imediato do Direito, todavia, a efetivação desta norma só terá eficácia, diante da atuação da igualdade material onde as desigualdades deverão ser observadas e, por conseguinte, reparadas.

A naturalização das diferenças construídas socialmente entre homens e mulheres é fundamental para essa atuação supostamente neutra do direito. Ao propor um tratamento formalmente igualitário para as mulheres, o Estado o faz partindo de diferenças que se materializam em desigualdades e em desvantagens para as mulheres e, dessa forma, a igualdade materializa-se como injustiça. (OLIVEIRA, 2017, p. 21).

Assim, o tratamento equivalente entre os sexos não reduz as diferenças existentes, mas acaba, pois, por reforçar as distorções existentes, eis o que se extrai das lições da jurista Flávia Piovesan (2018, p. 434):

Com o processo de especificação do sujeito de direito, mostra-se insuficiente tratar o indivíduo de forma genérica, geral e abstrata. Torna-se necessária a especificação do sujeito de direito, que passa a ser visto em suas peculiaridades e particularidades. Nessa ótica, determinados sujeitos de direito, ou determinadas violações de direitos, exigem uma resposta específica, diferenciada. Nesse sentido, as mulheres devem ser vistas nas especificidades e peculiaridades de sua condição social. Importa o respeito à diferença e à diversidade, o que thes assegura um tratamento especial.

Diante do exposto e em que pese o sistema adotado no Brasil, seja o modelo positivista, isto é, a civil law, ainda existe uma distanciamento no cumprimento efetivo destas leis, haja vista que o Brasil é signatário de pactos de proteção ao direitos das mulheres, como a Convenção Sobre a Eliminação de Todas as Formas de Discriminação contra as Mulheres (CEDAW) e a Convenção de Belém do Pará, dentre outros diplomas internacionais, que asseguram a proteção e a igualdade entre os sexos, a aplicabilidade destes diplomas ainda está longe de alcançar uma efetividade prática.

Se de um lado a Constituição brasileira e os tratados internacionais de proteção dos direitos da mulher consagram a igualdade entre homens e mulheres, o dever de promover essa igualdade e proibir discriminações, parte dos diplomas infraconstitucionais adota uma perspectiva androcêntrica (segundo a qual a perspectiva masculina é a central e o homem é o paradigma da humanidade) e discriminatória com relação à mulher. (PIOVESAN, 2018, p. 469).

Ocorre que não se pode perder de vista o fato de que a lei positivada não é suficiente para que surtam os efeitos necessários, pois é imperioso que o operador do direito não somente conheça a existên- 
cia da lei, mas a ponha em prática. Todavia, a práxis jurídica nos mostra que apesar de todos os avanços legislativos, internacionais e nacionais, ainda existe um déficit muito grande quanto à aplicação, haja vista que as leis são novas, mas a formação dos operadores do Direito ainda é focada numa metodologia e numa perspectiva antiga. Sobre isto, vale destacar as lições de Flávia Piovesan (2018, p. 471):

Há pesquisas científicas que demonstram o perfil altamente conservador dos agentes jurídicos que, em sua maioria, concebem o Direito como instrumento de conservação e contenção social e não como instrumento de transformação social. Esse perfil conservador dos agentes jurídicos tem fomentado a reprodução de estruturas e categorias jurídicas tradicionais, construídas há quase um século, o que tem inviabilizado a tarefa de reconstrução do pensamento jurídico à luz de novos paradigmas e novas interpretações. Essa postura implica uma gravíssima distorção jurídica, na medida em que dispositivos igualitários e que transformam a condição jurídica da mulher, previstos na Constituição Federal e em tratados internacionais ratificados pelo Brasil, são interpretados à luz de categorias discriminatórias veiculadas por diplomas infraconstitucionais.

Conforme essa autora, constata-se que o conservadorismo do operador do direito constitui um verdadeiro entrave para a aplicação dos diplomas legislativos em favor das mulheres, pois sua postura conservadora e androcêntrica impede a aplicação direta de leis que asseguram direitos para as mulheres, na busca por uma sociedade igualitária e justa, onde se tenha no horizonte a construção de uma justiça de gênero (SILVA; WRIGHT, 2016).

Nesta linha, percebe-se que o direito acaba por funcionar como perpetuador de distorções de gênero, quando deixa de ser utilizado para promover a igualdade material e a equiparação social. Em consonância com o art. $3^{\circ}$, IV da Constituição Federal de 1988, que traz em seu bojo os seus objetivos de uma sociedade livre, sem preconceitos ou discriminação de cor, sexo, ou idade, a introdução do feminismo enquanto instrumento de transformação do direito é medida imperiosa para se atingir tal propósito.

O feminismo, enquanto movimento social que já tem mais de três séculos de história, ainda, se faz pertinente, necessário e atual, pois, hodiernamente é reconhecido como movimento mais influente do século XX, tendo adentrado em diversas áreas da ciências, trazendo questionamentos, lançando luzes teóricas sobres diversos temas e problemas sociais, gerando transformações inovadoras e emancipatórias para as relações humanas em geral (SILVA, 2018).

Assim e embora tenha uma difusão enérgica em diversas áreas da ciência, na seara jurídica o feminismo tem sido introduzido de maneira lenta, dado o caráter hermenêutico, elitista e pretensamente neutro do campo jurídico (SILVA, 2018). Por isso, as relações entre o feminismo e o direito sempre foram muito conturbadas, tendo em vista que ao longo da história as feministas transitaram entre a denúncia, a reformulação, a desconstrução e o uso estratégico do saber/fazer jurídico, buscando garantir a igualdade de gênero.

Vale pontuar que no final do século XVIII, o feminismo já vinha denunciando o sexismo presente nas leis e no discurso jurídico que à época se manifestava por meio da negação de direitos civis e políticos para as mulheres, pela noção de diferença sexual para justificar os limites impostos à universalidade de direitos individuais. 
Com o passar dos anos, as opiniões feministas com relação a função e a utilidade do direito foram se diversificando e se tornando mais complexas, ao tempo que discordantes, pois em dado momento 0 direito é visto como mecanismo de dominação masculina e em outro momento é visto como instrumento para aprimoramento da cidadania feminina e às vezes ambas as visões convivem simultaneamente.

Apesar da relação conturbada entre o direito e o feminismo, nem todas as perspectivas feministas foram ou são completamente céticas em relação ao direito, haja vista que em termos de direitos das mulheres, toda conquista jurídica emana de uma crítica eficaz. Salete Maria da Silva (2018), enquanto pioneira na teorização do conceito de feminismo jurídico no Brasil, cita Jaramillo (2000) e traz algumas classificações acerca da crítica feminista ao Direito. De acordo com ela, a autora colombiana apresenta esta crítica em três momentos ou perspectivas.

Na primeira, há uma problematização da teoria do direito propriamente dito (questionando os pressupostos do direito e suas noções fundamentais), na segunda há críticas a institutos jurídicos enquanto mantenedores da subalternidade social e na terceira há um questionamento do modo como o direito é aplicado nos casos concretos, propondo usos estratégicos das leis.

Na primeira perspectiva, o Direito é tido como produto das sociedades patriarcais, refletindo interesses masculinos. Desta forma, mesmo quando o direito contempla os interesses ou demandas das mulheres, continua sendo aplicado por instituições e profissionais moldados pela ideologia patriarcal. Na segunda, a crítica feminista se direciona a determinadas instituições onde as normas jurídicas servem para excluir as mulheres como destinatárias de direitos civis, políticos e socais e econômicos.

Já na terceira, segundo Silva (2018), a crítica se direciona ao modo como o direito é aplicado, buscando apontar o androcêntrismo e o sexismo presente nas práticas e decisões judiciais. Desta forma, a autora apresenta e advoga pela adoção de metodologias feministas alternativas aos métodos hegemônicos, sugerindo formação em gênero para os educandos em direito e capacitação para os que já exercem a profissão, como forma de facilitar a mudança de percepção de normas e sua própria atuação profissional.

Segundo Silva (2018), a visão de que o Direito é sexista, encontra correspondência com a primeira onda do feminismo, também conhecido como feminismo de igualdade, surgido durante a revolução francesa e vicejante até o final da primeira guerra mundial, como única vertente feminista, inspirada em princípios iluministas e liberais. Neste momento, acreditava-se que o direito deveria ser neutro, abstrato e universal, a fim de tratar de maneira igual todas as pessoas. Defendia-se a supressão de leis discriminatórias com relação às mulheres e lutava-se pelas reformas jurídicas.

Ainda conforme a autora, a segunda visão concebe o direito como masculino, e é tida como correspondente à segunda onda do feminismo que também foi conhecido como feminismo da diferença e feminismo cultural, ganhando forças entre 1960 e 1980 estando presente até os dias de hoje. Esta segunda onda faz duras críticas ao direito, por concebê-lo intrinsecamente masculino e instrumento da dominação patriarcal. Apesar disto, defende leis que reconheçam as especificidades e necessidades femininas, mas desconfia das reformas estritamente legais, luta por transformações culturais e estruturais na sociedade assim como no mundo jurídico (SILVA, 2018).

Salete Silva ainda explora a terceira visão, que identifica o Direito como sexuado ou gendrado, decorrente da terceira onda do feminismo, chamado de feminismo pós-moderno, donde se percebe o 
Direito como uma tecnologia de gênero, isto é, como algo que tanto constrói o gênero como é construído por ele. Desta forma, as feministas desta época pugnam por um direito que respeite a diversidade sociocultural existente no mundo, inclusive entre as mulheres. Assim, segundo Silva (2018), esta visão enxerga o Direito muito mais como um discurso do que como uma norma, caracterizando-o como indeterminado, inconsistente e ambíguo.

As contribuições de Silva (2018) oferecem uma introdução bastante didática ao feminismo jurídico, e, diante de suas exposições, é possível perceber que o feminismo está se aproximando cada vez mais da seara jurídica, "estabelecendo uma relação de crítica mútua, mas também de importantes e exitosas parcerias", para usar as palavras da autora.

Isto dito, urge falar, portanto, do feminismo jurídico, enquanto terminologia desprovida de definição, mas que apresenta um consenso quanto a sua materialização já que se concretiza por meio da produção teórica, do ensino jurídico e da própria prática profissional. De acordo com Silva (2018, p. 98), “o feminismo jurídico enquanto campo de reflexão teórica e de prática que se encontra em constante crescimento na América Latina, já é possível perceber uma crescente inserção do pensamento feminista no mundo do direito, em especial nas últimas décadas”.

Silva sustenta, entendendo a complexidade do feminismo enquanto fenômeno, a existência e o reconhecimento do feminismo jurídico, enquanto uma vertentes do feminismo, que também necessita da produção teórica, tão importante para alimentar e orientar a ação, mas por outro lado, sua existência e consolidação exige também a práxis jurídicas, além de um conjunto de ações destinadas ao compartilhamento e socialização da proposta (2018).

Desta forma, "o feminismo jurídico como qualquer outro feminismo caracteriza-se pela pluralidade, heterogeneidade e ausência de consensos, o que lhe permite desenvolver diferentes perspectivas e abordagens" (SILVA, 2018, p. 88).

Salete Maria da Silva (2018, p. 90) assim define o feminismo jurídico:

Um conjunto de críticas, teorizações, proposições metodológicas e atividades práticas desenvolvidas por juristas feministas em face do fenômeno jurídico, dentro ou fora do sistema de justiça. A proposta central se direciona da desenvolver ações que promovam transformações radicais no âmbito das normas, discursos e práticas jurídicas tendo como foco a obtenção da igualdade de gênero.

Conforme autora, é necessário destacar que o pensamento jurídico feminista, por meio do seu esforço em prol da incorporação do gênero no âmbito estatal, tem sido adotado não somente para pensar o Direito, enquanto conjunto de normas positivadas, mas enquanto discurso e práxis jurídica profundamente marcados pela justaposição genérica.

Diz a referida autora que a pouca utilização da terminologia "feminismo jurídico" em comparação com "teoria feminista do direito" denota a dificuldade que algumas feministas encontram de se contrapor o sistema vigente, tendo em vista que o termo "feminismo jurídico", segundo ela, "tem como propósito desmascarar e criticar o patriarcado, oculto detrás de um direito e de uma teoria pretensamente neutra em relação ao gênero. Ou seja, visa desvelar o que podemos chamar de teoria patriarcal 
do direito, encoberta pela proteção da teoria do direito" (SILVA, 2018, p. 93).

Vale lembrar que do mesmo modo que a teoria feminista do direito, o ativismo jurídico feminista visa pôr em relevo os equívocos e as injustiças legais e jurídicas, fazendo com que as reflexões saiam do papel e ganhe materialidade.

Coincidimos com esta reflexão, pois entendemos que na atualidade se faz importante e necessário colocar ênfase no termo "movimento", já que segundo Silva, ele contribui para evidenciar as inúmeras ações que são realizadas com vistas a transformar o campo jurídico.

Salete Maria afirma que o feminismo jurídico

[...] pode ser definido como uma espécie de ativismo jurídico que incorpora a perspectiva de gênero, utilizando-se de estratégias políticas feministas para atua neste campo, orientando as demandas individuais e coletivas e/ou auxiliando as lutas travadas na seara do direito, dentro e fora do sistema de justiça. (SILVA, 2018, p. 95).

\section{CONSIDERAÇÕES FINAIS}

O direito gendrado, patriarcal e androcêntrico se encontra ultrapassado e decrépito, não sendo mais razoável a sua aplicabilidade para concretizar os objetivos traçados pelo Brasil por meio de seus diplomas legais nacionais e internacionais.

Desnaturalizar o androcentrismo presente no campo jurídico e propor reflexões que levem a uma mudança de mentalidade e de atitude, é tarefa que se impõe a todos que estudam e/ou militam no campo do Direito, bem como das teorias feministas e nos movimentos sociais de defesa dos direitos das mulheres, pois todos e todas têm poder/dever de elevar a discussão a um novo patamar, incorporando as lentes de gênero ao campo jurídico e levando o pensamento jurídico feminista aos movimentos sociais, notadamente de mulheres.

A mudança de paradigma se faz enquanto medida urgente e necessária, onde é imprescindível reformular os paradigmas do direito não apenas no que concerne às leis postas (vez que as inovações jurídicas são cada vez maiores), há que se considerar que é essencial ultrapassar o entrave jurídico do operador do direito, que impede a lei de alcançar sua concretude.

É importante concluir que a antiga visão que vinculava a mulher à esfera privada contribui para manter as relações assimétricas de gênero no mundo da família e na esfera pública, bem como a intolerância reforçada por padrões normativos que obrigavam indivíduos a se enquadrarem em papéis e identidades de gêneros instituídos, a fim de manter o projeto de dominação-exploração masculina e os padrões androcêntricos.

Nesta linha, o feminismo jurídico, teorizado no Brasil por feministas como Salete Maria da Silva, constitui-se de um saber e uma ação elementar para a transformação das relações de gênero, sobretudo via sistema de justiça, na medida em que traz a mudanças de perspectiva e não somente isto, mas é o instrumento capaz de romper com as estruturas rígidas do direito gendrado. 
A crítica jurídica trazida pelo feminismo jurídico, assim como as propostas de ação concreta são capazes de promover a emancipação por meio do Direito, haja vista que toma este como aliado do movimento feminista, sem se iludir com as tramas e complexidades do campo jurídico, ainda hegemonicamente androcêntrico e patriarcal. Porém, nada, absolutamente nada, é impossível de ser transformado.

\section{REFERÊNCIAS}

CAMPOS, Carmen Hein. Razão e sensibilidade: teoria feminista do direito e Lei Maria da Penha. Disponível em: http://www.compromissoeatitude.org.br/wpcontent/uploads/2014/02/1_1_razao-esensibilidade.pdf. Acesso em :15 jan. 2019.

FACIO, Alda. Hacia otra teoría crítica del Derecho. Disponível em http://www.flacso.org.ec/docs/ safisfacio.pdf Acesso em: 30 jan. 2019.

FACIO, Alda. Los derechos humanos desde una perspectiva de genero y las políticas publicas. Otras Miradas, Universidad de los Andes, Mérida, Venezuela, v. 3, n. 1, p. 15-26, jun. 2003. Disponible en: http://www.redalyc.org/articulo.oa?id=18330102. Acesso em: 25 jan. 2019.

MELLO, Adriana Ramos de. A Importância da formação dos operadores do direito em violência de gênero e direitos humanos, como instrumento de acesso à Justiça. Disponível em: http://www. emerj.tjrj.jus.br/revistaemerj_online/edicoes/revista57/revista57_59.pdf. Acesso em: 25 jan. 2019.

OLIVEIRA, Tatyane Guimarães. Feministas ressignificando o direito: desafios para aprovação da Lei Maria da Penha. Rev. Direito e Práx., Rio de Janeiro, v. 8, n. 1, p. 616-650, 2017. ISSN: 2179-8966. Disponível em: http://www.scielo.br/pdf/rdp/v8n1/2179-8966-rdp-8-1-0616.pdf. Acesso em: 2 fev. 2019.

PIOVESAN, Flávia. Temas de direitos humanos. 11. ed. São Paulo: Saraiva Educação, 2018.

SCOTT, Joan. Gênero: uma categoria útil de análise histórica. Educação e Realidade, p. 71-99, jul./ dez. 1995. Disponível em: m:http://www.4shared.com/get/XCWKugpJ/joan_Scott_-_Gnero_uma_ categor.html;jsessionid=DCADFA8C27E7F9BC503AE12DBE4F2532.dc210. Acesso em: 4 fev. 2019.

SILVA, Salete Maria da. Feminismo Jurídico: uma introdução. Disponível em: https://portalseer. ufba.br/index.php/cadgendiv/article/view/25806. Acesso em: 30 jan. 2019.

SILVA, Salete Maria da; WRIGHT, Sonia J. Uma reflexão feminista sobre o conceito de justiça de gênero. Disponível em: http://www.indexlaw.org/index.php/revistateoriasjustica/article/view/1086/ pdf. Acesso em: 30 jan. 2019. 
SILVA, Salete Maria da. Eleições 2018: o lugar das mulheres nas chapas majoritárias. Disponivel em: https://portalseer.ufba.br/index.php/cadgendiv/ article/view/29349. Acesso em: 30 jan. 2019.

1 Graduada em Direito; Advogada e extensionista do Observatório de Pacificação Social da Universidade Federal da Bahia - UFBA. E-mail: cdvscadvogados@gmail.com

2 Graduada em Direito; Advogada e membro da Comissão da Diversidade Sexual da Ordem dos Advogados do Brasil, Subseção de Feira de Santana no Estado da Bahia. E-mail: brunalaispinto@gmail.com

3 Advogada feminista; Doutora em Estudos Interdisciplinares sobre Mulheres, Gênero e Feminismo; Mestre em Direito; Professora da Universidade Federal da Bahia - UFBA; Líder do JUSFEMINA - grupo de pesquisa e ação em direitos das mulheres e políticas para igualdade de gênero. E-mail: saletemaria@oi.com.br

\section{(). (1) (2)}

Este artigo é licenciado na modalidade acesso abertosob a Atribuição-Compartilhalgual CC BY-SA

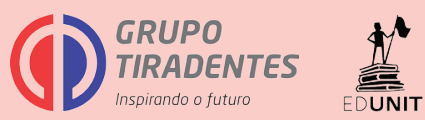

